\title{
Prescripción de acciones laborales: cuestiones de fondo y de forma
}

\section{Statute of limitation of labor actions: substance and form issues}

\section{MANOEL CARLOS TOLEDO FILHO*}

\begin{abstract}
Resumen: El presente trabajo busca situar la figura jurídica de la prescripción en el contexto general del derecho laboral, en orden a investigar su compatibilidad con los preceptos fundamentales de esa rama específica de la legislación, identificando, además, las características, limitaciones y plazos adoptados a ese respecto por los países iberoamericanos, en especial aquellos integrantes del Cono Sur.
\end{abstract}

Palabras clave: prescripción - derecho laboral - acciones laborales

Summary: This study aims to place the statute of limitation legal definition in the general context of labor law analyzing its compatibility with fundamental precepts of that specific legislation area: identifying also features, boundaries and deadlines adopted by Ibero-American countries, mainly members of the southern cone.

Key words: statute of limitation - labor law - labor actions

CONTENIDO: I. INTRODUCCIÓN.- II. ASPECTOS DE FONDO.- III. ASPECTOS DE FORMA.- IV. CONCLUSIONES.

\section{INTRODUCCIÓN}

El tema referente a la prescripción de los créditos laborales $\multimap$ o de la acción judicial destinada a cobrarlos_ - parece plantear una suerte de contradicción estructural cuando es analizado en confrontación con los principios fundamentales que hacen a la esencia del derecho del trabajo. Realmente, nadie duda que, en el ámbito de la legislación del trabajo, la irrenunciabilidad de los derechos atribuidos por las leyes al trabajador funciona como un auténtico mecanismo de control o de equilibrio en una relación contractual que es genéticamente desequilibrada a favor del empleador, en la medida en que este tiene el poder económico y de

\footnotetext{
* Bachiller, magíster y doctor por la Facultad de Derecho de la Universidad de San Pablo. Magistrado laboral desde 1990, ejerciendo actualmente el cargo de Camarista del Tribunal Regional del Trabajo de Campinas/SP (décimo quinta región). Miembro efectivo de la Asociación Argentina de Derecho del Trabajo y de la Seguridad Social (AADTSS). Miembro efectivo de la Asociación Uruguaya de Derecho del Trabajo y de la Seguridad Social (AUDTSS). Miembro honorario de la Asociación de Abogados Laboralistas del Paraguay. Correo electrónico: neco@mpcnet.com.br
} 
dirección de la empresa mientras que el empleado dispone únicamente de su fuerza de labor.

Ahora bien, el instituto de la prescripción no es más que una suerte de renuncia tácita a una ventaja establecida por el ordenamiento positivo en favor de alguien que, por cuenta de su supuesto desinterés en la persecución del derecho que le corresponda ${ }^{1}$, perderá los respectivos mecanismos legales de cobro, sin perjuicio de que el presunto deudor luego cumpla espontáneamente la obligación (hipótesis que la teoría permite pero la práctica desconoce).

En esos términos, y considerando que muchas veces el trabajador no posee una garantía de permanencia o estabilidad en su empleo, no es difícil intuir que no se arriesgará a perder su fuente de sustento personal y familiar para demandar a su empleador mientras la relación laboral siga en curso. Podrá ocurrir, entonces - y con muchísima frecuencia, definitivamente ocurre-que múltiples incumplimientos de la legislación laboral acaben consolidados por el solo transcurso del tiempo².

No es por casualidad, pues, que los demandantes que a menudo se encuentran en los juzgados del trabajo no sean propiamente empleados, sino exempleados. Así, en España, Carmen Sáez Lara registra que, como regla «el trabajador es el demandante y el empresario el demandado» ${ }^{3}$. En Uruguay, esclarece Juan Raso Delgue que el actor «en la práctica procesal es siempre la parte trabajadora» ${ }^{4}$; en Perú y en Venezuela, la misma impresión nos es transmitida por, respectivamente, Luis Vinatea Recoba ${ }^{5}$ Eric Lorenzo Pérez Sarmiento ${ }^{6}$.

1 Sin embargo, cabe registrar, como hace Diego Tosca, que en la doctrina existe la advertencia de que la figura en estudio no podría ser considerada "un avasallamiento o una excepción a la irrenunciabilidad, ya que, como afirmara Santoro Passareli, la prescripción no depende directamente de la voluntad del titular, sino que se fundamenta en el interés público que el ordenamiento estima más prominente que el que justifica la irrenunciabilidad del derecho por parte del titular, con lo cual llega a la conclusión de que en la prescripción el derecho se extingue por voluntad de la ley» (ToscA, Diego Martín (coord.). Tratado de derecho del trabajo. Tomo l: Teoría general del derecho del trabajo. Santa Fe: Rubinzal-Culzoni, 2005, p. 377). Pero, como ese mismo autor luego esclarece «no puede desconocerse la limitación real que experimenta el trabajador para exigir el cumplimiento de derechos desconocidos durante el desarrollo de la relación» (p. 378).

2 Como ha expresado Mario Garmendia, la brevedad de los plazos de prescripción "genera una paradoja desde el punto de vista axiológico, pues pretendiendo amparar al bien jurídico "seguridad" (llevándole una rápida tranquilidad al deudor de créditos laborales) en realidad termina provocando graves situaciones de "inseguridad" (en la contraparte acreedora del crédito laboral), porque posee la potencialidad de generar en el primero la irresistible tentación de eludir el cumplimiento de las normas laborales y aguardar que el simple transcurso del tiempo vaya depurando inexorablemente los incumplimientos contumaces» (Eficacia práctica de las normas laborales. Montevideo: Fundación de Cultura Universitaria (FCU), 2005, p. 95).

3 SÁEZ LARA, Carmen. La tutela judicial efectiva y el proceso laboral. Madrid: Civitas Ediciones, 2004, p. 37.

4 RASO Delgue, Juan. «El principio protector en el proceso del trabajo». En PLÁ RodríGUEZ, Américo (ed.). Derecho procesal del trabajo, treinta estudios. Montevideo: FCU, 2005, p. 57.

5 VINAETA RECOBA, Luis. «Análisis funcional de la ley procesal del trabajo: condicionantes de la eficacia del proceso laboral». FERRO DELGADO, Víctor (coord.). Balance de la reforma laboral peruana. Lima: Sociedad Peruana de Derecho del Trabajo y de la Seguridad Social, 2001, p. 299.

6 PéRez Sarmiento, Eric Lorenzo. Comentarios a la ley orgánica procesal del trabajo. Segunda edición. Caracas: Vadell Hermanos Editores, 2004, p. 23. 
De modo que, antes aun de empezar a verificar las circunstancias y las características que tenga la figura de la prescripción en los distintos niveles de la legislación estatal, hay que registrar una advertencia preliminar. Quizás estemos ante un instituto que, en rigor, no debería existir en la materia laboral, es decir, no debería ni siquiera estar sujeto a algún margen de discusión legal, doctrinal o jurisprudencial.

\section{ASPECTOS DE FONDO}

En el derecho material brasileño, los plazos de prescripción de las deudas laborales están previstos en el artículo 7, apartado XXIX de la Constitución Federal, donde se establece como uno de los derechos de los trabajadores la «acción, cuanto a los créditos resultantes de las relaciones de trabajo, con plazo de prescripción de cinco años para los trabajadores urbanos y rurales, hasta el límite de dos años después de la extinción del contrato de trabajo».

Esa misma regla es reproducida por el artículo 11 de la Consolidación de las Leyes del Trabajo (CLT) de Brasil.

Es conveniente mencionar cuatro situaciones especiales:

1. La situación del trabajador accidentado: hay dudas en la doctrina y en la jurisprudencia en cuanto a si resultan aplicables los plazos de la Constitución o los plazos del Código Civil o, incluso, si en tal situación no se estaría frente a un derecho de naturaleza imprescriptible, por su vinculación a la propia dignidad de la persona humana.

2. La de los aportes destinados al Fondo de Garantía del Tiempo de Servicio (FGTS) para los cuales la Ley 8036, en su artículo 23, dispone un plazo de prescripción de treinta años.

3. En relación con las demandas cuyo objetivo sea, exclusivamente, hacer prueba del tiempo de servicio para efectos de obtener beneficios relacionados a la seguridad social, la CLT (artículo 11) establece que no hay aplicación de los plazos de prescripción.

4. Finalmente, es importante consignar que, en el ordenamiento brasileño, no transcurre ningún plazo de prescripción en relación con los trabajadores que tengan menos de dieciocho años de edad (CLT, artículo 440).

Si bien la situación brasileña en ese asunto está lejos de poder ser considerada ideal, parece cierto, de otro lado, que la normativa de Brasil, en tal punto específico, es un poco mejor que la de sus países hermanos del Cono Sur. 
a) En la República Argentina, el artículo 256 de la Ley de Contrato de Trabajo (LCT) dispone que «prescriben a los dos (2) años las acciones relativas a créditos provenientes de las relaciones individuales de trabajo y, en general, de disposiciones de convenios colectivos, laudos con eficacia de convenios colectivos y disposiciones legales o reglamentarias del Derecho del Trabajo».

b) El Código de Trabajo (CT) paraguayo, en su artículo 399, dispone que «las acciones acordadas por este Código o derivadas del contrato individual o colectivo de condiciones de trabajo, prescribirán al año de haber ellas nacido»?

c) El Código de Trabajo (LCT) chileno, en su artículo 510, establece que «los derechos regidos por este Código prescribirán en el plazo de dos años contados desde la fecha en que se hicieron exigibles» ${ }^{8}$.

d) En la República Oriental del Uruguay, la Ley 18091, en su artículo 2 , dispone que «los créditos o prestaciones laborales prescriben a los cinco años, contados desde la fecha en que pudieron ser exigibles».

Una circunstancia importante que no puede dejar de ser debidamente registrada es que en las normativas chilena y uruguaya, del mismo modo que en la normativa brasileña, el legislador estableció, más allá de los plazos generales de prescripción, una suerte de «fecha límite» o «fecha máxima», que está directamente relacionada con el momento del término o de la extinción de la relación de trabajo. En Brasil, el límite es de dos años; en Chile, seis meses ${ }^{9}$ y en Uruguay, un año ${ }^{10}$.

Como se puede fácilmente advertir, los ordenamientos en cuestión claramente acortaron sus plazos de prescripción utilizando como fundamento, para ese efecto, el hecho central o esencial de la terminación del contrato de trabajo. ¿Y por qué lo hicieron? La respuesta es sencilla: porque presumieron que, después del término de la relación de dependencia, el trabajador ya no tendría las naturales limitaciones que su estado de subordinación crea en relación con su empleador, y, por lo tanto, estaría libre o liberado para ejercer sus derechos.

7 Un año es plazo general que otrosí prevé la tradicional Ley Federal del Trabajo de México, en su artículo 516: «Las acciones de trabajo prescriben en un año, contado a partir del día siguiente a la fecha en que la obligación sea exigible, con las excepciones que se consignan en los artículos siguientes». En ese mismo sentido tenemos el artículo 12 del Código de Trabajo de Panamá.

8 En el caso de Chile, llama la atención el plazo específico - y muy corto- establecido para el cobro de las horas extraordinarias: apenas seis meses «contados desde la fecha en que debieron ser pagadas». En Panamá, el asunto funciona al revés, el plazo de prescripción para el cobro de las horas extraordinarias — cuando no se trate de un «trabajador de confianza»— es de cinco años (CT, artículo 12-A), o sea, es significativamente superior al plazo general de un año.

9 CT, artículo 510: «En todo caso, las acciones provenientes de los actos y contratos a que se refiere este Código prescribirán en seis meses contados desde la terminación de los servicios".

10 Ley 18.091, artículo 1: «Las acciones originadas en las relaciones de trabajo prescriben al año, a partir del día siguiente a aquel en que haya cesado la relación laboral en que se fundan». 
En puridad, es aquí que los legisladores de esos países, en cierta medida, se traicionan a sí mismos. Involuntariamente admiten que durante el tiempo del contrato de trabajo hay un serio impedimento para que el empleado demande judicialmente sus créditos laborales. Pero, precisamente porque las cosas son así, entonces la medida más lógica a implementar sería no estipular ningún plazo de prescripción mientras estuviera en vigor la relación de trabajo.

\section{ASPECTOS DE FORMA}

En Brasil, el entendimiento predominante es que la prescripción laboral, para ser reconocida judicialmente, depende de una alegación expresa de la parte interesada (normalmente el empleador). Ese aspecto, que siempre fue considerado sencillo, pasó a ser objeto de alguna controversia a partir del año 2006, por causa de una modificación realizada en el Código de Proceso Civil (CPC) brasileño, según la cual el juez deberá pronunciar o reconocer, «de oficio» (ex officio), la ocurrencia de la prescripción (artículo 219, apartado quinto). Es decir, hubo, en este aspecto y en la dimensión del proceso civil brasileño, una equiparación entre las figuras de la prescripción y de la caducidad del derecho.

El problema que entonces se presentó era saber si existiría compatibilidad entre ese precepto legal y la normativa laboral. La respuesta, a nuestro juicio, es claramente negativa, y esa parece ser la tendencia actual de la jurisprudencia del Tribunal Superior del Trabajo (TST). Desde una perspectiva general, es posible constatar que diversos ordenamientos establecen que los plazos de prescripción serán interrumpidos o suspendidos por la promoción de una demanda judicial o, incluso, de una reclamación administrativa o extrajudicial. Esa circunstancia nosotros la podemos encontrar, por ejemplo, en las normativas argentina (LCT, artículo 257), uruguaya (ley 18.091, artículos 3 y 4), paraguaya (CT, artículo 404, «a»), chilena (CT, artículo 510), española (Ley de la Jurisdicción Social, artículos 65 y 73), mexicana (Ley Federal del Trabajo, artículo 521, I) venezolana (Ley Orgánica del Trabajo, artículo 52), colombiana (CT, artículo 489), panameña (CT, 127) y brasileña (CLT, artículo 625-G; Código Civil, artículo 202; CPC, artículo 219).

En el caso específico de Brasil, la jurisprudencia del Tribunal Superior del Trabajo ha entendido que la presentación de la demanda judicial, aun cuando la misma fuere archivada, interrumpe el plazo de prescripción, pero lo hace solamente en relación con los «pedidos idénticos». Es decir, habiendo la proposición de una segunda demanda, se considerará que hubo interrupción del plazo de prescripción exclusivamente cuanto a las postulaciones (pedidos) que sean iguales a los que existían en la primera demanda. Una disposición similar puede ser encontrada en el artículo 510 del Código del Trabajo chileno. 


\section{CONCLUSIONES}

El insigne jurista mexicano Néstor de Buen, después de registrar que en «el fondo parece que sí hay una contradicción entre la aceptación de la prescripción y las finalidades proteccionistas y tutelares que pueden reconocerse a los derechos de los trabajadores», concluye, sin embargo, con apoyo en la doctrina de Radbruch, que la prescripción es necesaria por una razón de seguridad jurídica, una vez que, sin ella, «la vida de las relaciones laborales sería intolerable y no habría tiempo más que para atender a los conflictos, sin que existiera capital que pudiera hacerles frente» ${ }^{11}$.

Esa concepción parece haber prevalecido en la generalidad de los ordenamientos laborales. Incluso, en algunos casos, con una suerte de retroceso o involución de la normativa positiva, que fue cambiada en orden a reducir los plazos de prescripción de los derechos de los trabajadores. Así, en Brasil, los trabajadores rurales, para los cuales hasta el año 2000 no existía prescripción durante el tiempo del contrato, tuvieron su situación igualada a la de los trabajadores urbanos por fuerza de una modificación introducida aquel año en la Constitución Federal. En Chile, bajo el régimen del Código de Trabajo de 1931 «no corría plazo de prescripción alguna - salvo para el cobro de horas extraordinarias- durante la vigencia del contrato de trabajo ${ }^{12}$. En la República Uruguaya, el plazo de prescripción llegó a alcanzar los veinte años, fue reducido a un año, aumentado posteriormente a diez y luego disminuido a dos, antes de la entrada en vigencia de la ley $18091^{13}$.

Volvemos, entonces, a la reflexión anticipada en la introducción del texto: a nuestro juicio, no hay cómo superar la contradicción estructural a la que conlleva la irrenunciabilidad de los derechos laborales en la figura de la prescripción. En realidad, como muy bien advertía Óscar Ermida, la reducción de los plazos de prescripción «constituye una forma de desregulación por deslizamiento, indirecta o encubierta, pero terriblemente eficaz, ya que recurriendo a un instrumento no laboral - en el caso, procesal_ - produce el inmediato cercenamiento de un importante cúmulo de derechos del trabajador ${ }^{14}$. En ese contexto, prestigiar la seguridad de las relaciones jurídicas implicaría desprestigiar a la persona del trabajador. Implicaría, por lo tanto, afectarlo en su dignidad en cuanto ser humano ${ }^{15}$.

11 De BuEn, Néstor. Derecho del Trabajo. Tomo primero. Décimo sexta edición. México: Porrúa, 2004, pp. 656-657.

12 Thayer ARTEAga, William. Texto y comentario del código del trabajo. Santiago de Chile: Editorial Jurídica de Chile, 2002, p. 422.

13 CAStello, Alejandro \& Natalia Colotuzzo. «Régimen de prescripción laboral. Análisis de la ley № 18091 ». Derecho Laboral, L, 225 (2007), p. 234.

14 ERMIDA, Óscar. «La flexibilidad laboral», (http://www.ccee.edu.uy/ensenian/catpype/materialad/ laboral.PDF), 2000.

15 Como asevera Mario Garmendia «en el ámbito del Derecho del Trabajo, la protección del bien jurídico "seguridad" —que, como se dijo, se tutela mediante el instrumento de la prescripción extintiva— debe 
Así, hay que, sino expurgar, por lo menos restringir el alcance de tal figura en los ordenamientos laborales. A ese respecto, los ejemplos que nos parecen adecuados mencionar son la Constitución Política de Bolivia (2009, apartado IV de su artículo 48) ${ }^{16}$, la Ley Orgánica del Trabajo de Venezuela (2012, artículo 51) ${ }^{17}$, y la normativa peruana del año 2000 (ley 27321, artículo único ${ }^{18}$. Incumbe pues a los demás países del continente examinar con atención las legislaciones de nuestros hermanos del norte de los Andes ${ }^{19} \mathrm{y}$, en la máxima medida posible, incorporar tal contenido en los respectivos ordenamientos.

resultar compatible con la protección del bien jurídico "trabajo", valor este último que se presenta como el núcleo central de la disciplina y que, en consecuencia, merece ser destinatario de un amparo preferente y superlativo" (Cinco temas sobre prescripción de los créditos laborales. Segunda edición. Montevideo: FCU, 2005, pp. 19-20).

16 «Los salarios o sueldos devengados, derechos laborales, beneficios sociales y aportes a la seguridad social no pagados tienen privilegio y preferencia sobre cualquier otra acreencia, y son inembargables e imprescriptibles".

17 «Las acciones provenientes de los reclamos por prestaciones sociales prescribirán al cumplirse diez años contados desde la fecha de terminación de la prestación de los servicios de conformidad con lo establecido en la Constitución de la República Bolivariana de Venezuela. El resto de las acciones provenientes de la relación de trabajo prescribirán al cumplirse cinco años, contados a partir de la fecha de terminación de la prestación de los servicios. En los casos de accidente de trabajo o de enfermedad ocupacional, el lapso de prescripción de cinco años se aplicará conforme a lo establecido en la Ley Orgánica de Prevención, Condiciones y Medio Ambiente de Trabajo».

18 «Las acciones por derechos derivados de la relación laboral prescriben a los 4 (cuatro) años, contados desde el día siguiente en que se extingue el vínculo laboral». Aun sobre ese tema, el Código de Trabajo de Portugal (2009), establece en su artículo 337 que el crédito del empleador o del trabajador resultante del contrato de trabajo, de su violación o cesación prescribe después de transcurrido un año desde la fecha de la terminación del contrato. Esa es, asimismo, la regla general prevista en el Estatuto de los Trabajadores de España (artículo 59). Comentando tal precepto, observan María del Mar Serna Calvo y Anna Ginés Fabrellas que «en definitiva, la ley laboral introduce una causa de suspensión del cómputo respecto al régimen civil común atendiendo al estado de subordinación del trabajador" (Estatuto de los trabajadores: comentado y con jurisprudencia. Bajo la dirección de Salvador del Rey Guanter. Segunda edición. Madrid: La Ley, 2007, p. 1230).

19 La normativa ecuatoriana también posee un criterio asemejado previsto en el artículo 635 del código de trabajo: «Prescripción de las acciones provenientes de actos o contratos. Las acciones provenientes de los actos y contratos de trabajo prescriben en tres años, contados desde la terminación de la relación laboral, sin perjuicio de lo dispuesto en los artículos que siguen y en los demás casos de prescripción de corto tiempo, especialmente contemplados en este Código". Colombia, sin embargo, puede ser considerada una excepción en ese tema, ya que, según el artículo 488 de su Código Sustantivo del Trabajo, el plazo general de prescripción NO se cuenta desde la terminación del contrato: «Las acciones correspondientes a los derechos regulados en este código prescriben en tres (3) años, que se cuentan desde que la respectiva obligación se haya hecho exigible, salvo en los casos de prescripciones especiales establecidas en el Código Procesal del Trabajo o en el presente estatuto". 